\title{
COUGH
}

\section{Cough in the community: a cross sectional survey and the relationship to gastrointestinal symptoms}

A C Ford, D Forman, P Moayyedi, A H Morice

See end of article for authors' affiliations

......................

Correspondence to: Professor A H Morice, Division of Academic Medicine, University of Hull, Castle Hill Hospital, Cottingham, East Yorkshire HU16 5JQ, UK: a.h.morice@hull.ac.uk

Received 31 January 2006 Accepted 22 June 2006 Published Online First 29 June 2006

\begin{abstract}
Background: The prevalence and severity of chronic cough in the community is uncertain. In a large population of representative normal subjects, we explored the relationship between self-reported cough severity and frequency, and factors known to be related to the aetiology of chronic cough. In particular, we have examined the relative association between cough and symptoms of gastrointestinal disease.

Methods: A cross-sectional survey was undertaken in 36 general practices with subjects randomly selected from practice computer databases. Baseline lifestyle and demographic characteristics were recorded. Participants were asked how often in the previous 2 months they had experienced bouts or spasms of coughing. Cough symptom status was dichotomised into symptomatic using a cut off of bouts or spasms of coughing at a frequency of between once a week and once a day or above. Gastrointestinal data were collected using validated methodology.

Results: Questionnaires were sent to 6416 subjects and 4003 (62\%) responded. The prevalence of chronic cough was $12 \%$, and was severe in $7 \%$. Following multivariate analysis, regurgitation (OR $1.71 ; 99 \% \mathrm{Cl}$ 1.20 to 2.45 ) and irritable bowel syndrome (OR 2.00; $99 \% \mathrm{Cl} 1.47$ to 2.72 ) were strong predictors of cough. Smoking (OR 1.61 ; $99 \% \mathrm{Cl} 1.18$ to 2.19), declining social class (OR 1.63 ; $99 \% \mathrm{Cl} 1.04$ to 2.57 ), and quality of life at baseline (OR $1.63 ; 99 \% \mathrm{Cl} 1.13$ to 2.35 ) were also significantly associated.

Conclusion: Chronic cough is a common symptom in the general population. Its strong association with gastrointestinal disease may have aetiological significance.
\end{abstract}

\section{METHODS}

\section{Study population}

The study was a cross-sectional survey performed as part of a 10 year follow up of individuals recruited into a population
Helicobacter pylori screening and treatment programme. This was conducted in Leeds and Bradford, cities in West Yorkshire, UK with a combined population of approximately 1200 000. The original study started in 1994 with 2 years of follow up. Recruitment was via 36 general practices, with subjects aged 40-49 years randomly selected from the practice computer databases. This age group was chosen to maximise the prevalence of $H$ pylori infection in the individuals under study. Over 30000 people were contacted originally, of whom 8407 attended and were eligible for inclusion in the study. These individuals were invited to attend for screening for $H$ pylori by 13-carbon labelled urea breath test. ${ }^{13}$ Exclusion criteria for the original study included receiving antibiotics or bismuth within the last 2 weeks or proton pump inhibitors (PPIs) within the last week; a documented allergy to macrolides, 5-nitroimidazoles, or PPIs; concomitant treatment with warfarin, theophylline, digoxin, anticonvulsants, and antihistamines; and those who were unable to abstain from alcohol for 1 week.

In order to trace those involved, the general practices that recruited the individuals were visited and their databases accessed to obtain a current address for all participants. Those successfully located were sent questionnaires by post. Informed written consent to access the primary care records was requested. Non-responders were sent a second postal questionnaire. The local research ethics committees in Leeds and Bradford approved the study in March 2003, and questionnaires were sent out in August 2003.

\section{Data collection}

Baseline lifestyle factors and demographic characteristics for study participants including age; sex; marital status; ethnicity; tobacco, alcohol, and coffee consumption; social class

Abbreviations: BMI, body mass index; IBS, irritable bowel syndrome; NSAID, non-steroidal anti-inflammatory drug 
(as defined by occupation); and H pylori status were stored on file from the original study.

In addition, at study entry participants completed a copy of the psychological and general well-being index (PGWBI), ${ }^{14}$ a validated quality of life scale consisting of 22 questions, with a higher score indicating a better health status. Baseline quality of life data were split into three equal sized groups according to total PGWBI score: low (scores 31-100); medium (101-112); and high (113 and above).

At 10 year follow up, participants were asked how often in the previous 2 months they had experienced bouts or spasms of coughing. Responses were rated on a 5-point Likert scale (not at all; less than once a month; between once a month and once a week; between once a week and once a day; and once a day or more). To explore the association of cough frequency with other variables, cough symptom status was dichotomised into symptomatic or asymptomatic, using a cut off point of bouts or spasms of coughing at a frequency of between once a week and once a day and above. Cough severity was assessed by enquiring how often the symptoms had interfered with normal activities of daily living in the previous 2 months on a comparable 5-point Likert scale.

Dyspepsia data at 10 years were collected using the short form Leeds dyspepsia questionnaire (S-FLDQ). The S-FLDQ assesses both the frequency and severity of four symptomsindigestion, heartburn, regurgitation, and nausea (all of which are rated on a 5-point Likert scale identical to that used for the cough question) - as well as asking the subject to identify the most troublesome of these four symptoms. This questionnaire has been previously validated and is acceptable, reliable, and responsive. ${ }^{15}$ In addition, it is selfadministered, which makes it ideal for use in a postal survey. Individual symptom status was dichotomised into symptomatic or asymptomatic for both heartburn and regurgitation, using a symptom frequency of once a month to once a week and above to define symptomatic.

A second questionnaire used the Manning criteria for the diagnosis of irritable bowel syndrome (IBS). ${ }^{16}$ It enquired about the presence of six symptoms: abdominal pain eased by defecation; stool frequency when abdominal pain commenced; loose stools when abdominal pain commenced; tenesmus; mucus per rectum; and abdominal distension. Symptom frequency was rated on a 3-point Likert scale (never; occasionally; or more than once a week). Individuals were defined as having IBS if they provided a positive response to any of the six symptoms at a frequency of more than once a week.

Finally, participants were asked to give their current weight (in $\mathrm{kg}$ ) and their height (in metres) to allow calculation of their body mass index (BMI) at 10 years. These were divided into three categories: normal (18.5-24.9); overweight (25-29.9); and obese (30 or more). Data on nonsteroidal anti-inflammatory drug (NSAID) and/or aspirin use in the preceding year were also obtained, but only for those individuals allowing access to their primary care records.

\section{Sample size}

The original power calculation was based on the expected prevalence of $H$ pylori and the difference in dyspepsia rates predicted in those receiving eradication treatment compared with placebo. This is not the relevant outcome for this study. Retrospective sample size calculations were performed to determine the power of the study. A sample size of 3300 subjects would detect an odds ratio of cough of 1.5 between cases (subjects with reflux symptoms and/or IBS) and controls at the $80 \%$ power and $5 \%$ significance level. This assumes that $10 \%$ of controls report chronic cough and IBS and/or reflux symptoms are present in at least $20 \%$ of the population.

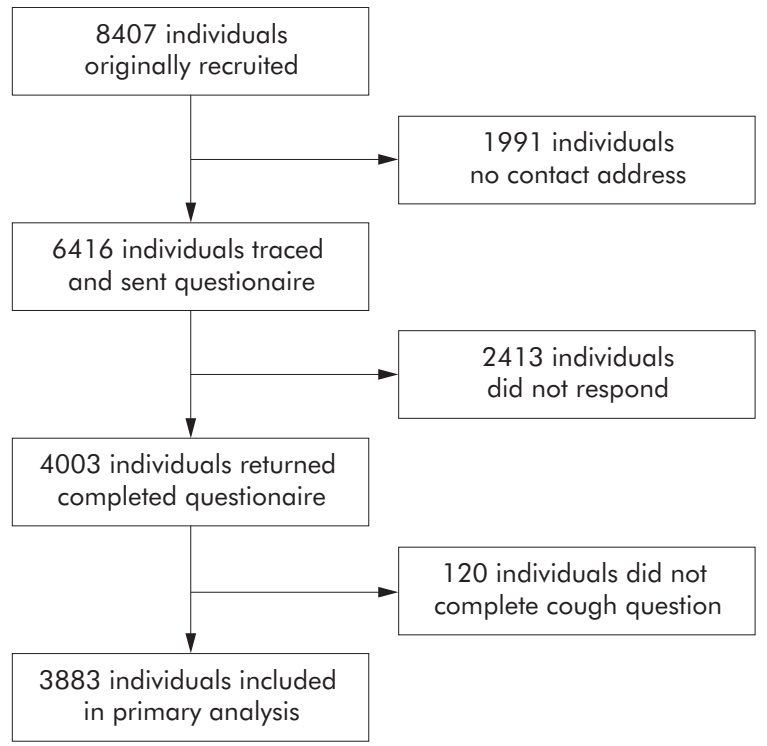

Figure 1 Flow of study participants at 10 year follow up.

\section{Statistical analysis}

The associations between demographic data, lifestyle factors, gastro-oesophageal reflux (including the individual symptoms of heartburn and regurgitation), quality of life, IBS, and NSAID and/or aspirin use and the presence of cough were explored using univariate analysis. Age and presence of cough were analysed using the Student's $t$ test and expressed as the mean difference with $99 \%$ confidence intervals (CI). Independent risk factors for the presence of cough were determined by performing multivariate logistic regression, controlling for all demographic data, lifestyle factors, symptoms of gastro-oesophageal reflux, quality of life, and presence of IBS (NSAID and/or aspirin use were not examined in these analyses as data were only available for those who had given consent to review their primary care records). Due to a priori concerns regarding multiple comparisons being made, a two tailed $p$ value of $<0.01$ was considered to be statistically significant, and the results of univariate and multivariate analyses were expressed as odds ratios (OR) with $99 \%$ CI.

All statistical analyses were performed using StatsDirect statistical software version 2.2.5 (StatsDirect Ltd, Sale, Cheshire, UK), and SPSS for Windows version 11.5 (SPSS Inc, Chicago, Illinois, USA).

\section{RESULTS}

Of the 8407 original participants, 1991 (24\%) could not be traced to a current address. Questionnaires were sent to the remaining 6416 and 4003 (62\%) responded, $3246(81 \%)$ to the first questionnaire. Of those who responded, 3883 (97\%) completed the cough question (fig 1). We were less likely to successfully contact males, smokers, and those with dyspepsia at baseline, and more likely to contact those of higher social class. The demographic data of those who responded are given in table 1 .

Cough frequency in the previous 2 months was reported as never by $59 \%$, less than monthly by $20 \%$, between monthly and weekly by $9 \%$, between weekly and daily by $7 \%$, and daily by $5 \%$. The overall prevalence of chronic cough (defined as greater than weekly coughing bouts) in the population under study was therefore $12 \%(\mathrm{n}=481)$. Cough severity affecting activities of daily living was reported as occurring never in $78 \%$, less than monthly in $11 \%$, between monthly and weekly in $4 \%$, between weekly and daily in $4 \%$, and daily 


\begin{tabular}{|ll|}
\hline Table 1 & Demographic data of responders \\
\hline & $\begin{array}{c}\text { Number }(\%) \text { of } \\
\text { individuals }\end{array}$ \\
\hline Female & $2179(56)$ \\
H pylori positive & $1048(27)$ \\
Married & $3621(93)$ \\
Smokers & $843(22)$ \\
Alcohol drinkers & $3536(91)$ \\
Coffee drinkers & $3336(86)$ \\
Caucasian & $3757(97)$ \\
Social class & $1500(39)$ \\
I and II & $1640(42)$ \\
III & $391(10)$ \\
IV and V & $1547(40)$ \\
Body mass index & $1448(37)$ \\
Normal & Overweight \\
Obese & $776(20)$ \\
\hline & \\
\hline
\end{tabular}

in $3 \%$. Cough severe enough to interfere with normal activities of daily living was therefore experienced on a daily or weekly basis in $7 \%(n=264$, fig 2$)$. When these data were examined according to sex, the prevalence of chronic cough was $13 \%(n=287)$ in women and $11 \%(n=194)$ in men, while severe cough was present in $7 \%(n=155)$ of women and $6 \%(\mathrm{n}=109)$ of men. The prevalence of cough occurring on a daily basis was significantly higher in women than in men $(6.2 \%(\mathrm{n}=135)$ v $4.6 \%(\mathrm{n}=78), \mathrm{p}=0.03)$.

Univariate analysis revealed several positive associations (table 2). Those with cough were more likely to have heartburn (OR 2.17; 99\% CI 1.65 to 2.85 ) and regurgitation at 10 year follow up (OR 2.61; 99\% CI 1.93 to 3.52). In addition, those with IBS were more likely to complain of cough (OR 2.93; 99\% CI 2.24 to 3.82). Lifestyle factors associated with cough included smoking tobacco (OR 1.91; 99\% CI 1.44 to 2.52), abstinence from alcohol (OR 1.83; 99\% CI 1.21 to 2.71 ), and obesity (OR $1.66 ; 99 \%$ CI 1.19 to 2.32 ). Finally, declining social class (OR 2.03; 99\% CI 1.33 to 3.06 for social class IV+V $v$ social class I+II) and quality of life at baseline (OR 2.26; 99\% CI 1.62 to 3.17 for low $v$ high) were both significantly associated with the presence of cough. Age appeared to have no significant impact on the presence of cough (mean difference in age between those with cough and those without $=0.31$ years; $99 \%$ CI -0.04 to $0.67, p=0.02$ ).

Following multivariate analysis, the presence of regurgitation (OR 1.71; 99\% CI 1.20 to 2.45 ) and IBS (OR 2.00; 99\% CI 1.47 to 2.72 ) at 10 years remained strong predictors of the presence of cough. Other significant associations included smoking (OR 1.61; 99\% CI 1.18 to 2.19 ), declining social class (OR 1.63; 99\% CI 1.04 to 2.57 for social class IV+V $v$ social class I+II), and quality of life at baseline (OR 1.63; 99\% CI 1.13 to 2.35 for low $v$ high). The presence of heartburn at 10 years as a predictor of cough approached statistical significance (OR 1.32; 99\% CI 0.95 to 1.83 ), as did obesity (OR 1.34; $99 \%$ CI 0.93 to 1.91 ).

\section{DISCUSSION}

Our study is the first to report the self-assessment of the frequency and severity of cough in the community. Previous surveys have sought to determine the prevalence of cough, but have not differentiated between the universal phenomenon of cough due to acute respiratory tract infection and chronic cough of other aetiology. By enquiring as to the frequency and severity of coughing bouts over the preceding 2 months, we attempted to select those individuals who have significant chronic cough but not those suffering from acute short lived upper respiratory tract infection (URTI) who we suggest would be unlikely to describe their cough as weekly

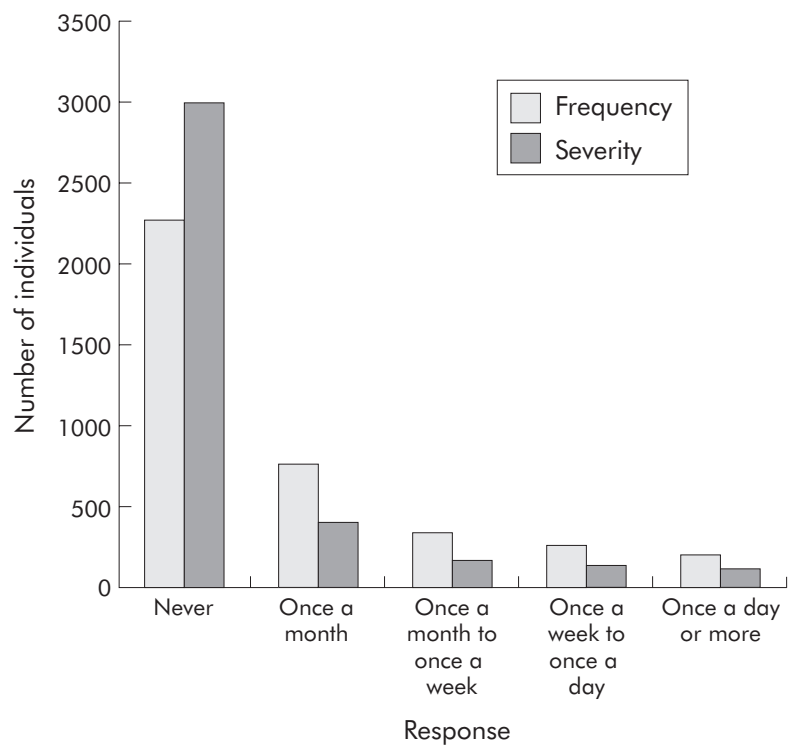

Figure 2 Frequency and severity of cough in all study subjects.

or daily. To minimise the confounding effects of URTI further, questionnaires were sent out in July and August so responses would be expected to reflect the nadir of seasonal URTI in England. ${ }^{17}$ The 12\% of individuals reporting the composite end point of daily and weekly cough emphasises the fact that chronic cough is one of the most common symptoms of medical importance.

Self-reported cough severity was used as a surrogate for the impact of chronic cough on quality of life. $7 \%$ of individuals reported daily or weekly chronic cough severe enough to interfere with activities of daily living. Previous studies have shown a marked decrement in quality of life with chronic cough, similar to that seen in patients with severe chronic obstructive pulmonary disease. ${ }^{7}$ Our study suggests that considerable psychosocial morbidity due to chronic cough is present within this representative population.

The primary aim of this study was to shed light on the association between chronic cough and gastrointestinal disease. We found a close association between self-reported chronic cough and the classic symptoms of gastro-oesophageal reflux, heartburn and regurgitation. It has become increasingly recognised that the manifestations of gastrooesophageal reflux disease are not confined to the classic symptoms of reflux, but can be associated with a number of extraoesophageal symptoms. Cough, voice disorders, and sinusitis have all been established as reflux related symptoms. ${ }^{18}$ Indeed, gastric contents may reflux as far as the middle ear. ${ }^{19}$ The clinical recognition of these extraoesophageal manifestations of reflux has been slow. This is explained in part by their relatively poor correlation to acidic reflux as manifest by heartburn. 24-hour $\mathrm{pH}$ monitoring studies in patients with gastro-oesophageal reflux disease have shown a good correlation between symptoms of heartburn and documented episodes of acid reflux. ${ }^{20}$ In contrast, oesophageal $\mathrm{pH}$ monitoring is poor at predicting response to treatment in reflux cough. ${ }^{12}$ Our finding of a relatively weak correlation between cough and heartburn confirms this observation and implies that non-acid reflux may be a more important factor in extraoesophageal reflux symptoms. We suggest that, while the known association between heartburn and acid reflux is correct, cough may also be precipitated by non-acid irritation of the upper airway. Thus, a better correlation was seen between cough and regurgitation-the other classic symptom of reflux disease. These latter 
Table 2 Univariate and multivariate analyses for presence of cough

\begin{tabular}{|c|c|c|c|c|c|}
\hline Variable & No (\%) with cough & $\begin{array}{l}\text { Unadjusted } \\
\text { OR }\end{array}$ & $99 \% \mathrm{Cl}$ & $\begin{array}{l}\text { Adjusted } \\
\text { OR† }\end{array}$ & $99 \% \mathrm{Cl}$ \\
\hline Age (per year) & & & & 1.05 & 1.00 to 1.10 \\
\hline \multicolumn{6}{|l|}{ Sex } \\
\hline Male & 194/1704 (11) & 1.00 & & 1.00 & \\
\hline Female & $287 / 2179$ (13) & 1.18 & 0.91 to 1.53 & 0.95 & 0.71 to 1.28 \\
\hline \multicolumn{6}{|l|}{ Heartburn } \\
\hline No & $305 / 2990(10)$ & 1.00 & & 1.00 & \\
\hline Yes & $176 / 889(20)$ & 2.17 & 1.65 to $2.85^{\star}$ & 1.32 & 0.95 to 1.83 \\
\hline \multicolumn{6}{|l|}{ Regurgitation } \\
\hline No & $347 / 3314(10)$ & 1.00 & & 1.00 & \\
\hline Yes & $133 / 568(23)$ & 2.61 & 1.93 to $3.52^{*}$ & 1.71 & 1.20 to $2.45^{*}$ \\
\hline \multicolumn{6}{|l|}{ Marital status } \\
\hline Married & $446 / 3621(12)$ & 1.00 & & 1.00 & \\
\hline Single & $29 / 208(14)$ & 1.15 & 0.64 to 1.95 & 1.23 & 0.67 to 2.24 \\
\hline \multicolumn{6}{|l|}{ Smoker } \\
\hline No & $318 / 2994(11)$ & 1.00 & & 1.00 & \\
\hline Yes & $156 / 843(18.5)$ & 1.91 & 1.44 to $2.52^{*}$ & 1.61 & 1.18 to $2.19^{*}$ \\
\hline \multicolumn{6}{|l|}{ Alcohol } \\
\hline Yes & $414 / 3536(12)$ & 1.00 & & 1.00 & \\
\hline No & $61 / 312(20)$ & 1.83 & 1.21 to $2.71^{*}$ & 1.27 & 0.81 to 1.99 \\
\hline \multicolumn{6}{|l|}{ Coffee } \\
\hline Yes & $400 / 3336(12)$ & 1.00 & & 1.00 & \\
\hline & $76 / 508(15)$ & 1.29 & 0.89 to 1.83 & 1.23 & 0.83 to 1.80 \\
\hline \multicolumn{6}{|l|}{ Ethnicity } \\
\hline White & $462 / 3757(12)$ & 1.00 & & 1.00 & \\
\hline Non-white & $11 / 74(15)$ & 1.25 & 0.46 to 2.86 & 1.10 & 0.41 to 2.95 \\
\hline \multicolumn{6}{|l|}{ Social class } \\
\hline$I+\|$ & $148 / 1500(10)$ & 1.00 & & 1.00 & \\
\hline III & $210 / 1640(13)$ & 1.34 & 1.00 to $1.81^{*}$ & 1.20 & 0.88 to 1.65 \\
\hline $\mathrm{IV}+\mathrm{V}$ & $71 / 391(18)$ & 2.03 & 1.33 to $3.06^{*}$ & 1.63 & 1.04 to $2.57^{*}$ \\
\hline \multicolumn{6}{|l|}{ IBS } \\
\hline No & $268 / 2914(9)$ & 1.00 & & 1.00 & \\
\hline Yes & $208 / 909$ (23) & 2.93 & 2.24 to $3.82^{*}$ & 2.00 & 1.47 to $2.72^{*}$ \\
\hline \multicolumn{6}{|c|}{ NSAID/aspirin use within last year } \\
\hline No & $320 / 2564(12.5)$ & 1.00 & & N/A & \\
\hline Yes & $84 / 606(14)$ & 1.13 & 0.79 to 1.59 & $\mathrm{~N} / \mathrm{A}$ & N/A \\
\hline \multicolumn{6}{|l|}{$H$ pylori status } \\
\hline Negative & $347 / 2835(12)$ & 1.00 & & 1.00 & \\
\hline Positive & $134 / 1048(13)$ & 1.05 & 0.79 to 1.39 & 0.85 & 0.62 to 1.17 \\
\hline \multicolumn{6}{|l|}{ BMI category } \\
\hline Normal & $167 / 1547(11)$ & 1.00 & & 1.00 & \\
\hline Overweight & $172 / 1448(12)$ & 1.11 & 0.82 to 1.51 & 1.00 & 0.72 to 1.38 \\
\hline Obese & $130 / 776(17)$ & 1.66 & 1.19 to $2.32^{*}$ & 1.34 & 0.93 to 1.91 \\
\hline \multicolumn{6}{|c|}{ Quality of life at baseline } \\
\hline High & $105 / 1244(8)$ & 1.00 & & 1.00 & \\
\hline Medium & $141 / 1247$ (11) & 1.38 & 0.97 to 1.98 & 1.32 & 0.91 to 1.92 \\
\hline Low & $215 / 1247$ (17) & 2.26 & 1.62 to $3.17^{*}$ & 1.63 & 1.13 to $2.35^{*}$ \\
\hline
\end{tabular}

IBS, irritable bowel syndrome; NSAID, non-steroidal anti-inflammatory drug; BMI, body mass index ${ }^{*} \mathrm{p}<0.01$.

†Following multivariate logistic regression.

symptoms may be more related to abnormal oesophageal motility and clearance. In population based studies such as ours, symptoms commonly overlap between individuals with endoscopic evidence of gastro-oesophageal reflux disease and those with gastrointestinal dysmotility. ${ }^{21}$ We have recently shown that there is a high degree of dysmotility in patients with reflux cough. ${ }^{22}$ Our additional and previously unreported finding of a close association between chronic cough and symptoms of IBS suggest the existence of a generalised disorder of gut motility causing symptoms from the top to the bottom!

The close association between self-reported cough and regurgitation seen in this study suggests that reflux may be one of the major aetiological factors for chronic cough. Indeed, 59\% of individuals who reported chronic cough also reported one classic symptom of reflux and $45 \%$ reported two.

Sex related differences in cough reflex have been described. Women are overrepresented in patients attending cough clinics and are more sensitive to cough challenge. ${ }^{23}$ It was therefore surprising that a similar percentage of men and women coughed on a daily or weekly basis. If, however, daily or more frequent cough was taken as the end point, women outnumbered men by 3:2. This frequency of troublesome cough may be more representative of the population presenting to cough clinics.

The link between obesity and chronic cough may again be through reflux mechanisms. With classic reflux symptoms, a high degree of correlation has been shown with increased BMI. ${ }^{24}$ Obesity increases the tendency for reflux to occur by mechanisms including hormonal and increased intra-abdominal pressure. ${ }^{24}$

The link between cough and smoking is hardly surprising and has been previously shown to be dose related. ${ }^{7}$ The precipitation of cough by cigarette smoke is likely to be due to the development of airway inflammation manifested as an increase in macrophages and cells expressing interleukin and adhesion molecule receptors. ${ }^{25}$ The consequence of this inflammation is an increase in the sensitivity of the cough reflex when frank bronchitis is present. ${ }^{26}$ However, this mechanism does not exclude reflux as a precipitant of coughing bouts in smokers. The act of cigarette smoking significantly increases reflux events. ${ }^{27}$

The impact of chronic cough on quality of life has recently been extensively documented. ${ }^{32}$ When patients with chronic 
cough are compared with those with severe chronic obstructive pulmonary disease, the impact on life quality is similar. ${ }^{2}$ However, we are unable to suggest whether the association between chronic cough and a lower quality of life seen in our study is a cause or consequence of the cough, particularly as quality of life was measured during the baseline study.

There are some limitations to this study. The fact that over half of those originally enrolled were either not successfully traced or did not respond to the questionnaire is almost inevitable when performing studies such as this, especially in a group of individuals who were randomly selected from the general population. There may therefore be differences between those who provided data and those who were lost to follow up, meaning that the population examined in this study is not entirely representative of the original sample of individuals. The restricted age range of subjects (now aged 50-59 years) means that the results might not be generalisable to any age group in the general population. There could also be a potential volunteer bias, where those who returned questionnaires at 10 years were more likely to be experiencing cough or dyspepsia symptoms at that point in time. This was certainly the case in the original study, where those who agreed to participate were more likely to have consulted their general practitioner with dyspepsia in the preceding 2 years than those who declined to participate. This could have resulted in the prevalence of cough and its relationship with gastro-oesophageal reflux disease being overestimated. However, as some individuals with gastro-oesophageal reflux induced cough may otherwise be asymptomatic, it is also possible that this association has been underestimated. Finally, the cough questionnaire used in the study had not been previously validated in terms of its ability to discriminate between acute and chronic cough although, as mentioned previously, the questionnaires were sent out in the summer months. There remains the possibility, however, that individuals reporting cough in this study may not be typical of patients with chronic cough.

In summary, $12 \%$ of our respondents had coughing bouts on at least a weekly basis. These subjects were significantly more likely to suffer from gastrointestinal symptoms characteristic of reflux disease. These findings support the hypothesis that gastro-oesophageal reflux is an important cause of chronic cough in the community.

\section{Authors' affiliations}

A C Ford, Centre for Digestive Diseases, Leeds General Infirmary, Leeds, UK

D Forman, Centre for Epidemiology and Biostatistics, Medical School, Leeds University, Leeds, UK

P Moayyedi, Gastroenterology Division, McMaster University, Health

Sciences Center, Hamilton, Ontario, Canada

A H Morice, Division of Academic Medicine, University of Hull, Castle Hill Hospital, Cottingham, East Yorkshire HU16 5JQ, UK

Funding: none.

ACF has no competing interests. DF has received speaker and consulting fees from AstraZeneca, Wyeth Laboratories and Takeda. PM has received speaker fees and research funds from AstraZeneca, Wyeth Laboratories, and Abbott Laboratories. AHM has received speaker fees and research funds from AstraZeneca, GlaxoSmithKline, and Merk Sharpe \& Dome.

\section{REFERENCES}

1 Morrell DC. Symptom interpretation in general practice. J R Coll Gen Pract 1972;22:297-309.

2 French CL, Irwin RS, Curley FJ, et al. Impact of chronic cough on quality of life. Arch Intern Med 1998;158:1657-61.

3 Birring SS, Prudon B, Carr AJ, et al. Development of a symptom specific health status measure for patients with chronic cough: Leicester Cough Questionnaire (LCQ). Thorax 2003;58:339-43.

4 Fuller RW, Jackson DM. Physiology and treatment of cough. Thorax 1990;45:425-30.

5 Loundon RG, Brown LC. Cough frequency in patients with respiratory disease. Am Rev Respir Dis 1967:96:1137-43.

6 Cullinan P. Persistent cough and sputum: prevalence and clinical characteristics in south east England. Respir Med 1992;86:143-9.

7 Janson C, Chinn S, Jarvis D, et al. Determinants of cough in young adults participating in the European Community Respiratory Health Survey. Eur Respir J 2001:18:647-54.

8 Irwin RS, Curley FJ, French CL. Chronic cough. The spectrum and frequency of causes, key components of the diagnostic evaluation, and outcome of specific therapy. Am Rev Respir Dis 1990;141:640-7.

9 Morice AH. Post-nasal drip syndrome: a symptom to be sniffed at? Pulm Pharmacol Ther 2004;17:343-5.

10 Morice AH. Epidemiology of cough. Pulm Pharmacol Ther 2002;15:253-9.

11 Mello CJ, Irwin RS, Curley FJ. Predictive values of the character, timing, and complications of chronic cough in diagnosing its cause. Arch Intern Med 1996;156:997-1003.

12 Patterson RN, Johnston BT, MacMahon J, et al. Oesophageal pH monitoring is of limited value in the diagnosis of "reflux-cough". Eur Respir $J$ 2004;24:724-7.

13 Moayyedi P, Feltbower R, Brown J, et al. Effect of population screening and treatment for Helicobacter pylori on dyspepsia and quality of life in the community: a randomised controlled trial. Leeds HELP Study Group. Lancet 2000;355: 1665-9.

14 Dupuy HJ. The Psychological General Well-Being (PGWB) Index. In: Wenger NK, Mattson, ME, Fruberg CF, eds. Assessment of quality of life in clinical trials of cardiovascular therapies. New York: Le Jacq Publishing, 1984:170-83.

15 Fraser A, Qume M, Ford AC, et al. Validation of short-form Leeds dyspepsia questionnaire (S-FLDQ) in a community setting. Gastroenterology 2003;124(Suppl 1):A224

16 Manning AP, Thompson WG, Heaton KW, et al. Towards positive diagnosis of the irritable bowel. BMJ 1978;2:653-4.

17 Office of Population Censuses and Surveys. Morbidity statistics from general practice: 4th national study 1991-1992, Series MB5, 3. London: HMSO 1995.

18 Koufman JA. The otolaryngologic manifestations of gastroesophageal reflux disease (GERD): a clinical investigation of 225 patients using ambulatory 24hour $\mathrm{pH}$ monitoring and an experimental investigation of the role of acid and pepsin in the development of laryngeal injury. Laryngoscope 1991;101:1-78.

19 Tasker A, Dettmar PW, Panetti M, et al. Reflux of gastric juice and glue ear in children. Lancet 2002;359:493.

20 Klauser AG, Schindlbeck NE, Muller-Lissner SA. Symptoms in gastrooesophageal reflux disease. Lancet 1990;335:205-8.

21 Thomson AB, Barkun AN, Armstrong D, et al. The prevalence of clinically significant endoscopic findings in primary care patients with uninvestigated dyspepsia: the Canadian Adult Dyspepsia Empiric Treatment - Prompt dyspepsia: the Canadian Adult Dyspepsia Empiric Treatment - Prompt
Endoscopy (CADET-PE) study. Aliment Pharmacol Ther 2003;17:1481-91.

22 Kastelik JA, Redington AE, Aziz I, et al. Abnormal oesophageal motility in patients with chronic cough. Thorax 2003;58:699-702.

23 Kastelik JA, Thompson RH, Aziz I, et al. Sex-related differences in cough reflex sensitivity in patients with chronic cough. Am J Respir Crit Care Med 2002;166:961-4.

24 Nilsson $M$, Johnsen $R, Y e W$, et al. Obesity and estrogen as risk factors for gastroesophageal reflux symptoms. JAMA 2003;290:66-72.

25 Turato G, Di Stefano A, Maestrelli P, et al. Effect of smoking cessation on airway inflammation in chronic bronchitis. Am J Respir Crit Care Med 1995; 152:1262-7.

26 Wong $\mathrm{CH}$, Morice $\mathrm{AH}$. Cough threshold in patients with chronic obstructive pulmonary disease. Thorax 1999:54:62-4.

27 Kadakia SC, Kikendall JW, Maydonovitch C, et al. Effect of cigarette smoking on gastroesophageal reflux measured by $24-\mathrm{h}$ ambulatory esophageal $\mathrm{pH}$ monitoring. Am J Gastroenterol 1995;90:1785-90.

28 French CT, Irwin RS, Fletcher KE, et al. Evaluation of cough-specific quality of life questionnaire. Chest 2002;121:1123-31. 